\title{
Inhibition of return to object-based and environment-based locations
}

\author{
BRADLEY S. GIBSON and HOWARD EGETH \\ Johns Hopkins University, Baltimore, Maryland
}

\begin{abstract}
Inhibition of return (IOR) has been described in terms of two functional components. The locationbased component is associated with descriptions of spatially fixed, environmental locations; the object-based component is associated with more abstract descriptions of spatially invariant objects. In the present study, we hypothesized that the location-based component may also be associated with descriptions of spatially invariant objects because, like environment-based descriptions, object-based descriptions have an intrinsic spatial structure. To test this hypothesis, we employed a computer-generated depiction of a brick that rotated in depth between the presentations of cue and target. The results of four experiments showed that IOR accrued to locations that remained fixed with respect to the brick as well as the environment, suggesting that both object-based and environment-based descriptions can influence location-based IOR.
\end{abstract}

Summoning covert attention to a spatial location with an external cue can either speed or slow the detection of a subsequent target. When the target follows the onset of the cue by 150 msec or less, reaction times (RTs) are typically faster when the target appears in the cued location than when it appears in an uncued location (Eriksen \& Yeh, 1985; Maylor, 1985; Posner \& Cohen, 1984; Posner, Cohen, Choate, Maylor, \& Hockey, 1984; Posner, Rafal, Choate, \& Vaughan, 1985; Rafal, Calabresi, Brennan, \& Sciolto, 1989). This facilitation is thought to reflect one consequence of orienting covert attention to a spatial location.

In addition to this facilitatory component, covert attentional orienting can have an inhibitory component as well. Posner and Cohen (1984) showed that RTs, which were initially faster to cued locations than to uncued locations, became slower following intervals of $300 \mathrm{msec}$ or more (Kwak \& Egeth, 1992a; Maylor \& Hockey, 1985; Rafal et al., 1989). Because responses were slower to locations to which covert attention had been previously summoned, Posner et al. (1985) termed this effect inhibition of return (IOR). This effect may reflect an adaptive bias in the visual system toward novel information, thereby increasing the efficiency with which spatial loci can be searched (Klein, 1988; Maylor, 1985; Posner \& Cohen, 1984; but see Wolfe \& Pokorny, 1990).

\footnotetext{
Support was provided by grants from the National Institute of Mental Health (T32-MH18215) to Johns Hopkins University, and from the National Science Foundation (BNS-8919554) and the Air Force Office of Scientific Research (ISSA-92-0041) to the second author. The authors would like to thank Bill Bacon, John Flowers, Peter Gerhardstein, Anne Hillstrom, David Irwin, Lester Krueger, Mary Peterson, and Trammell Neill for their helpful comments on earlier versions of this paper. Correspondence should be addressed to B. S. Gibson, Department of Psychology, University of Notre Dame, Notre Dame, IN 46556.
}

Since Posner and Cohen's (1984) seminal finding, IOR's role in visual processing has been explored in greater detail. These studies have included investigation of IOR's relation to other known processes such as attentional orienting (Kwak \& Egeth, 1992b; Maylor, 1985; Posner \& Cohen, 1984; Rafal et al., 1989) and eye movements (Abrams \& Dobkin, in press; Rafal et al., 1989); IOR's relation to various stimulus attributes (Kwak \& Egeth, 1992a); and IOR's dependence on task (Egly, Rafal, \& Henik, 1992; Terry, Valdes, \& Neill, 1992). Yet although much has been learned about IOR in these studies, many of its fundamental properties remain in question. One issue of particular interest concerns whether IOR is associated with descriptions of objects, locations, or both.

Although early experiments suggested that IOR was associated with spatial locations defined in fixed environmental coordinates (Maylor \& Hockey, 1985; Posner \& Cohen, 1984), these locations often coincided with objects (Tipper, Brehaut, \& Driver, 1990; Tipper, Driver, \& Weaver, 1991). For instance, in Posner and Cohen's study (1984), the relevant environmental locations were each defined by the contours of a square; cuing consisted of brightening (or dimming) the contours, and the target appeared in either the cued or the uncued square. Thus, IOR may have accrued to a shape description, to a description of the environmental location occupied by the square, or to both.

Tipper et al. (1991) dissociated objects and environmental locations by setting the squares in motion. Subjects fixated a central square around which two other squares revolved in a clockwise direction in such a way that neither object was associated with a particular environmental location. (The moving squares maintained their orientation as they revolved; i.e., they did not appear as diamonds after $45^{\circ}$ of revolution.) At a specific point in the revolu- 
tion, one entire square was cued by a transient brightening around its contours. Both squares then continued to revolve $90^{\circ}, 180^{\circ}$, or $270^{\circ}$ before the target-a small dot-appeared equiprobably inside one of the two squares.

The pattern of results obtained by Tipper et al. (1991) indicated that IOR was object-based, not location-based: RTs were consistently slower when the target appeared in the cued square than when it appeared in the uncued square, even when the squares had revolved $180^{\circ}-$ a revolution that brought the uncued square to the location where the cuing occurred (i.e., the cued environmental location). As such, Tipper et al.'s (1991) findings suggest that inhibition accrues exclusively to objects, though inhibition to objects and spatial locations need not be either/or. In fact, Tipper, Weaver, Jerreat, and Burak (in press) have recently obtained evidence for both location-based and object-based IOR within the same paradigm as that used by Tipper et al. (1991). At present, it is not clear why such discrepant results were obtained across the two Tipper et al. studies.

In short, the dichotomy between spatially fixed locations and spatially invariant objects appears to reflect an important functional dichotomy between two inhibitory components: a location-based component and an objectbased component. However, this functional dichotomy appears to imply that the spatial domain of IOR is restricted to environmental locations, which may be unwarranted. For the conception of an object as independent of location should not be understood to imply that an object is devoid of location (Baylis \& Driver, 1993; Farah, Brunn, Wong, Wallace, \& Carpenter, 1990). Indeed, an early outcome of visual object processing appears to be the computation of a structural description-a temporary representation of the stimulus object that includes an explicit specification of relative locations within an object (Hummel \& Biederman, 1992; Marr, 1982; Pinker, 1984; Rock, 1973).

Hence, while objects are themselves distinct from the fixed spatial locations that they occupy, there exist other, intraobject, locations that may remain fixed with respect to their parent object. ${ }^{1}$ From this standpoint, an object can be construed as a "microenvironment" whose distinct locations may be "tagged"' by the inhibitory mechanism. Evidence that IOR can accrue to locations such as these would be important, for it would extend the spatial domain of IOR beyond that previously considered, and, more generally, it would extend our understanding of how spatial and object processes interact in the visual system. In the remainder of this paper, we emphasize the spatial similarity between objects and locations by developing the notion that IOR can operate on different kinds of locations-those that remain fixed with respect to an object and those that remain fixed with respect to the environment.

\section{EXPERIMENT 1}

The stimulus employed in the present experiments is depicted in Figure 1. The "brick" depicted in Figure 1

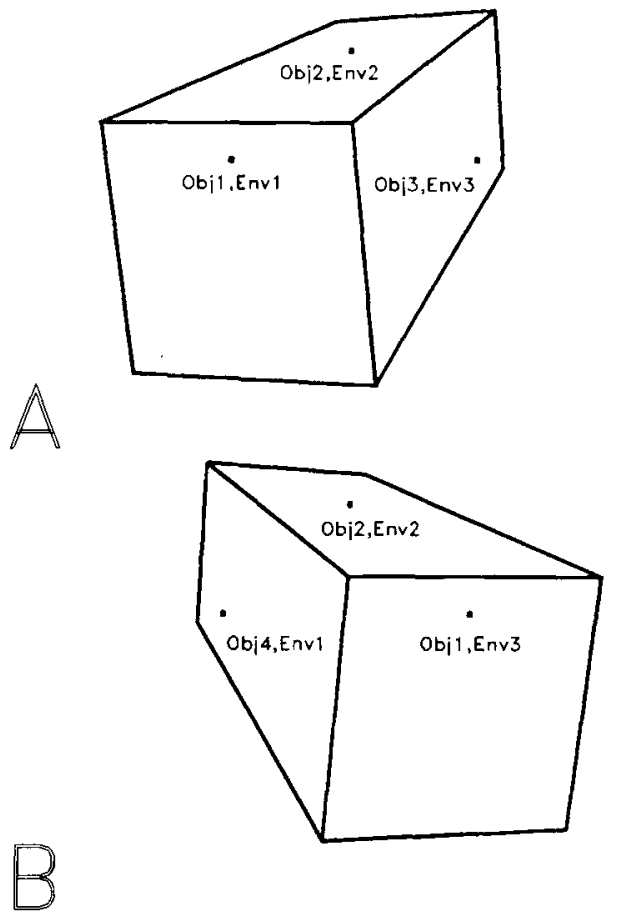

Figure 1. Two perspective views of the brick, illustrating the three object-based (Obj) and environment-based (Env) locations.

has six total surfaces, three of which are visible in each of the two poses. The brick in Figure 1A differs from the brick in Figure $1 \mathrm{~B}$ by a rigid transformation in depth (viz., rotation about the $y$-axis). Transformation of the stimulus was necessary in order to dissociate locations specified with respect to the brick from locations specified with respect to the environment (see below). We chose this type of transformation over other possible transformations because recent evidence suggests that at least some spatial relations specified within the structural description of an object are invariant across depth-rotation, as measured by object recognition in human observers (Biederman \& Gerhardstein, 1993).

Located on each of the three visible surfaces in Figures $1 \mathrm{~A}$ and $1 \mathrm{~B}$ is a dot. Together the dots illustrate the range of possible cue and target locations; however, the dots were never presented simultaneously as in Figure 1. On a typical trial, a single transient dot, the cue, appeared on one of the three surfaces in Figure 1A (1B) and the brick then appeared to rotate in depth to the location depicted in Figure 1B (1A). Shortly thereafter, another dot, the target, appeared on one of the three surfaces. The subjects' task was to press a key as soon as they detected the target.

Inhibition of return would be indicated by slower RTs when the cue and target share the same location (specified with respect to the brick, the environment, or both) than when they do not. The question of whether or not inhibition can accrue to locations specified with respect to the brick rests on the following two conditions, both 
of which receive empirical confirmation in the present paper. The first condition requires that the dots depicted in Figure 1 be assigned locations in the structural description of the brick that are more specific than a coarse description of the surface on which they appear (e.g., front, top, and side; see, e.g., Hummel \& Biederman, 1992). This relatively precise specification of location must be provided because each face of the brick might be considered as a more basic object than the brick as a whole; hence, it was necessary to show that inhibition could accrue to different locations within a single face of the brick lest location be confounded with object. Our evidence suggests that dots separated by at least $3^{\circ}$ of visual angle are represented as distinct, even though they may appear on the same face of the brick (see Experiment 4).

Accordingly, we have arbitrarily labeled the locations of the three dots in Figure 1A as Obj1, Obj2, and Obj3, to indicate this relatively precise specification of location with respect to the brick. Nevertheless, in order to facilitate discussion, we will often refer to the location of a dot simply in terms of the surface on which it appears: front, top, or side. Finally, we have also arbitrarily labeled the dots Env1, Env2, and Env3, respectively, to indicate the location of the dots as specified in fixed environmental coordinates, though it need not be assumed that the specification of location with respect to the brick and the specification of location with respect to the environment share exactly the same format.

The second condition concerns the invariant specification of these object-based locations across depth rotation. In particular, the invariant specification of location with respect to the brick requires that a dot specified in a particular location (e.g., location Obj1) continue to be specified as such across different views (see Figures 1A and 1B). This requirement is rooted in the need to dissociate locations specified by the brick from locations specified by the environment, thereby demonstrating that intraobject locations remained fixed to the brick. This dissociation is illustrated in Figure 1; the dot in location Obj1 is in environmental location Env1 in Figure 1A and in environmental location Env3 in Figure 1B.

Conversely, the dot in environmental location Env1 was initially in location Obj1 on the brick in Figure 1A, but is now in a new location on the brick, Obj4, in Figure 1B, thereby demonstrating the invariant specification of location with respect to the environment. ${ }^{2}$ Likewise, the dot in environmental location Env3 was initially in location Obj3 on the brick in Figure 1A, but is now in location Obj1 on the brick in Figure 1B. However, Env1 and Env3 may remain in the same environmental location before and after rotation only if their specification is independent of the change in depth associated with the brick's different surfaces. In the text below, we discuss in greater detail the consequences of this depth change. For now, it does no harm to think of environmental location in terms of locations on the surface of the screen.

In short, the purpose of Experiment 1 was twofold: First, we investigated whether IOR could be demonstrated when location remained fixed with respect to the brick (e.g., Obj1), despite a change in orientation. Accordingly, unlike in previous investigations into object-based IOR (Tipper et al., 1991), all locations probed in this experiment occurred within a single depicted three-dimensional object. Second, we also investigated whether IOR could be demonstrated when the cue and target shared the same fixed environmental location (e.g., Env1), but different object-based locations.

\section{Method}

Subjects. Twenty students at Johns Hopkins University participated in this experiment for pay. All subjects reported normal or corrected-to-normal vision. One subject's data were discarded because she reported depth reversals of the stimulus; consequently, the findings reported in Experiment 1 are based on a total of 19 subjects.

Stimuli and Apparatus. The ratio of the height, width, and length of the brick was approximately $1: 1: 3$. If viewed from the side, the brick appeared as a rectangle that subtended $5.7^{\circ} \times 16.2^{\circ}$ of visual angle at $50 \mathrm{~cm}$, the viewing distance used in this experiment. If viewed from the front, the brick appeared as a square that subtended $5.7^{\circ} \times 5.7^{\circ}$ of visual angle. Figure 2 depicts the 13 perspective views of the brick that were shown on each trial of Experiment 1 to create the impression of a brick rotating in depth.

The two initial starting positions of the brick are depicted in Figures $2 \mathrm{~A}$ and $2 \mathrm{M}$. These starting positions were obtained by rotating the brick, starting from a full side view, $72^{\circ}$ around a centrally located $y$-axis and $15^{\circ}$ around a centrally located $x$-axis. Thus, three surfaces were visible in the initial view of the brick. To facilitate discussion of this stimulus, we refer to these three surfaces as front, top, and side. Because the brick was rotated in depth, the top and side surfaces appeared foreshortened. The maximum horizontal and vertical extent of the brick on the screen ranged from $11.8^{\circ}$ and $11.3^{\circ}$, respectively (as in Figures $2 \mathrm{~A}$ and $2 \mathrm{M}$ ), to $8.5^{\circ}$ and $11.3^{\circ}$, respectively (as in Figure $2 \mathrm{G}$ ). Each of the intermediate views depicted in Figures $2 \mathrm{~A}-2 \mathrm{M}$ was obtained by rotating the brick an additional $3^{\circ}$ around the $y$-axis while the brick remained fixed along the $x$ - and $z$-axes. Thus, the brick was depicted as rotating a total of $36^{\circ}$ in depth on each trial. Note that the side surface was completely occluded beginning in the 5 th frame (see Figure 2E), whereas the other, previously occluded, side was exposed in the 10th and subsequent frames (see Figure 2J).

The fixation square was located at the junction between the front, top, and side of the brick in the initial and final frames. The fixation square subtended $0.5^{\circ} \times 0.5^{\circ}$ and remained in the same physical location on the screen throughout the brick's transformation (compare down each column in Figure 2). Thus, the location of the fixation square on the brick changed as the brick rotated.

The three possible locations of the cue and target are depicted in Figures $2 \mathrm{~A}$ and $2 \mathrm{M}$ and are the same three locations as those depicted in Figure 1. Cues and targets were white dots that subtended $0.2^{\circ}$ of visual angle; they could appear on the front, top, or side of the brick. Cues and targets appearing on the side of the brick were located $10.88 \mathrm{~cm}$ from the front of the brick (the actual physical brick was $14.5 \mathrm{~cm}$ in length) and were classified as far from the viewer in terms of apparent depth, but this dot appeared only $4.0^{\circ}$ from the center of the fixation square, owing to foreshortening. Cues and targets appearing on the top of the brick were located $9.67 \mathrm{~cm}$ from the front of the brick and were classified as in the middle in terms of apparent depth, but in terms of visual angle this dot appeared only $2.3^{\circ}$ from the center of the fixation square, owing to foreshortening. Cues and targets appearing on the front of the brick were near to the observer and appeared essentially in the frontal plane. They appeared $4.0^{\circ}$ from the center of the fixa- 

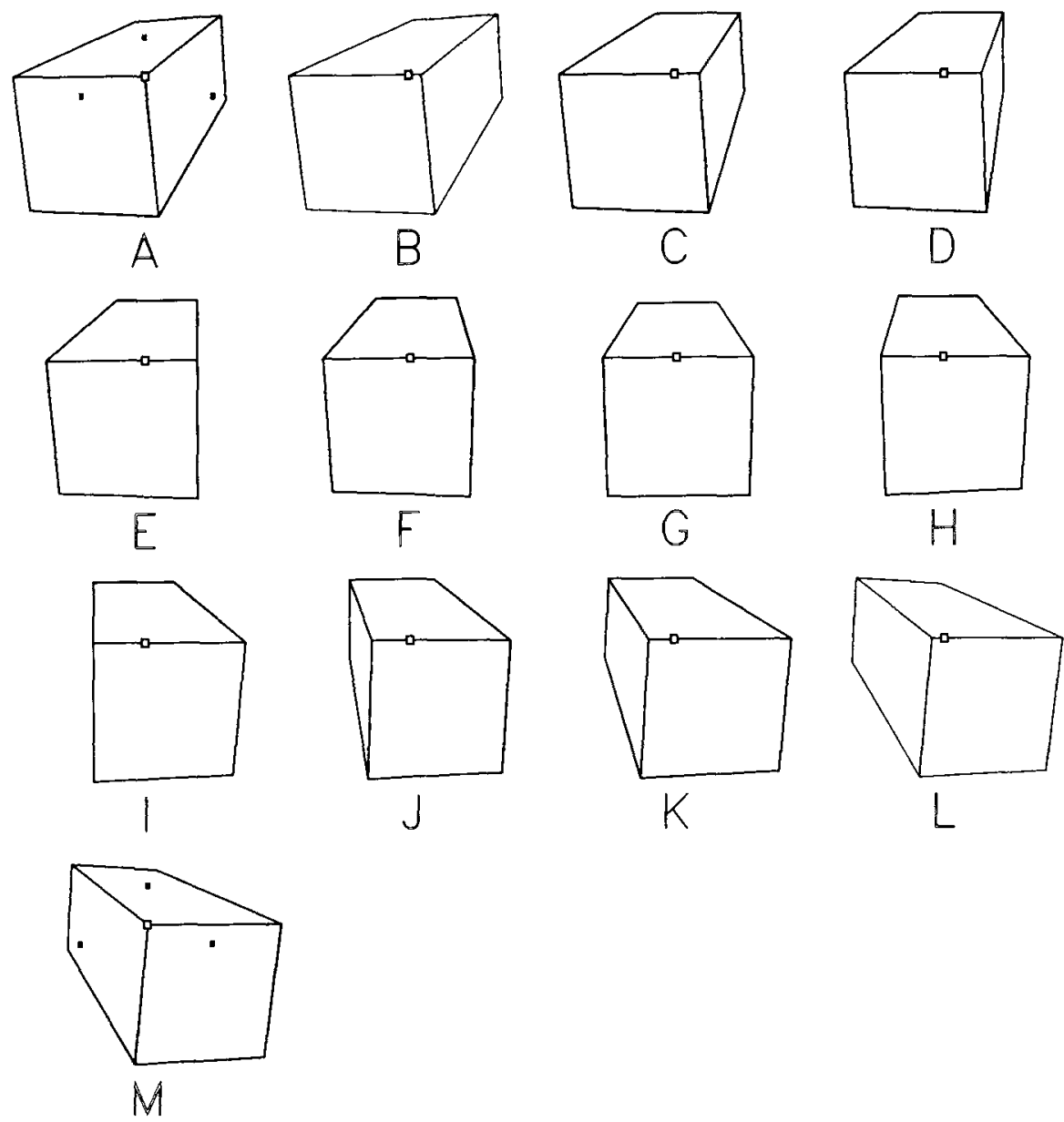

Figure 2. The 13 different perspective views of the brick shown in Experiment 1. Figures $2 A$ and 2M show the three possible cue and target locations; the cues and targets were never presented simultaneously.

tion square. In the remainder of the paper, the terms near, middle, and far will be used to describe the depth of a dot. ${ }^{3}$ The distance from fixation of each of the cues and targets, in terms of both visual angle and apparent depth, could not be equated across the three surfaces because of constraints in constructing the various cued conditions employed in the present experiment (see below).

The brick was drawn in white (the line width was $0.1^{\circ}$ of visual angle) on a black background. The stimuli were presented on a Zeos VGA monitor. Latencies were recorded by a Zeos 486 SLC microcomputer.

Procedure. The subjects were instructed to maintain fixation on the fixation square throughout each trial. The sequence of events that occurred on each trial was as follows. Half the trials began with the leftward-facing brick (Figure 2A), and the other half began with the rightward-facing brick (Figure $2 \mathrm{M}$ ). After $500 \mathrm{msec}$, a cue (a single, small white dot) appeared equally often on the front, top, or side of the brick for 114 msec. After a 100 -msec interval following the offset of the first cue, attention was brought back to fixation by the appearance of a second cue presented for $114 \mathrm{msec}$ inside the fixation square. Coincident with the onset of this second cue, the brick was made to move by sequentially presenting the 13 frames depicted in Figure 2 in the appropriate order (either $2 \mathrm{~A}$ to $2 \mathrm{M}$ or $2 \mathrm{M}$ to $2 \mathrm{~A}$ ). The first 12 frames were presented for approximately $29 \mathrm{msec}$ each; the second cue appeared during the first 4 frames. The final, 13th, frame was presented for either $43 \mathrm{msec}$ or $243 \mathrm{msec}$ before the target dot appeared, on two thirds of the trials, on either the front, top, or side of the brick. On the remaining one third of the trials, the target dot did not appear (catch trials). Thus, when the target dot did appear, it appeared either $600 \mathrm{msec}$ or $800 \mathrm{msec}$ after the onset of the first cue.

We manipulated stimulus onset asynchrony (SOA) so that subjects could not predict when the target dot would appear. The target dot remained on the screen until the subject responded, whereupon the display was erased. When the target dot did not appear, the brick remained on the screen for an additional $2 \mathrm{sec}$ before the display was terminated. Subsequent trials were presented automatically, following an intertrial interval of $2 \mathrm{sec}$. The subjects were required to press the shift key on the side of their dominant hand as soon as they detected the target dot. They were also informed that on one third of the trials, the target dot would not appear, and that they should withhold response in these cases. The subjects were told that responding when there was no target dot counted as an error, and that they should try to avoid errors. A chinrest ensured that viewing distance remained at $50 \mathrm{~cm}$ throughout the experiment. 
The subjects participated in a single experimental session that lasted approximately $45 \mathrm{~min}$.

Design. Nine conditions were created by the factorial combination of the three cue locations with the three target locations. These nine conditions are depicted graphically in Figure 3 (for the sake of simplicity, we show only the conditions in which the cue appeared on the leftward-facing brick and the target appeared on the rightward-facing brick). The conditions illustrated in Figure 3 are organized into three major groups, depicted horizontally across the page. Each group comprises two rows. The top row of each group shows the three possible cue locations-front, top, or side. The second row shows the location of the target dot, which remained constant within each group. Thus, the three groups were called the front target group, the top target group, and the side target group; within each group, the cue appeared equiprobably on the front, top, or side of the brick.
Within each of these three target position groups, there were cued conditions-trials in which the locations of the cue and the target were the same (with respect to the object, environment, or both)and there were uncued conditions-trials in which the locations of the cue and target were different (with respect to both the object and the environment).

When the target dot appeared on the front of the brick, one cued condition occurred when the cue and target appeared in the same location with respect to the brick, but in a different environmental location (labeled 1 in Figure 3); and, the other cued condition occurred when the cue and target appeared in the same location with respect to the environment, but in a different location with respect to the brick (labeled 3 in Figure 3). These two cued conditions were called the object condition and the environment condition, respectively, to indicate the basis of cuing; that is, the cue and target were in the same location with respect to the brick in the object condi-

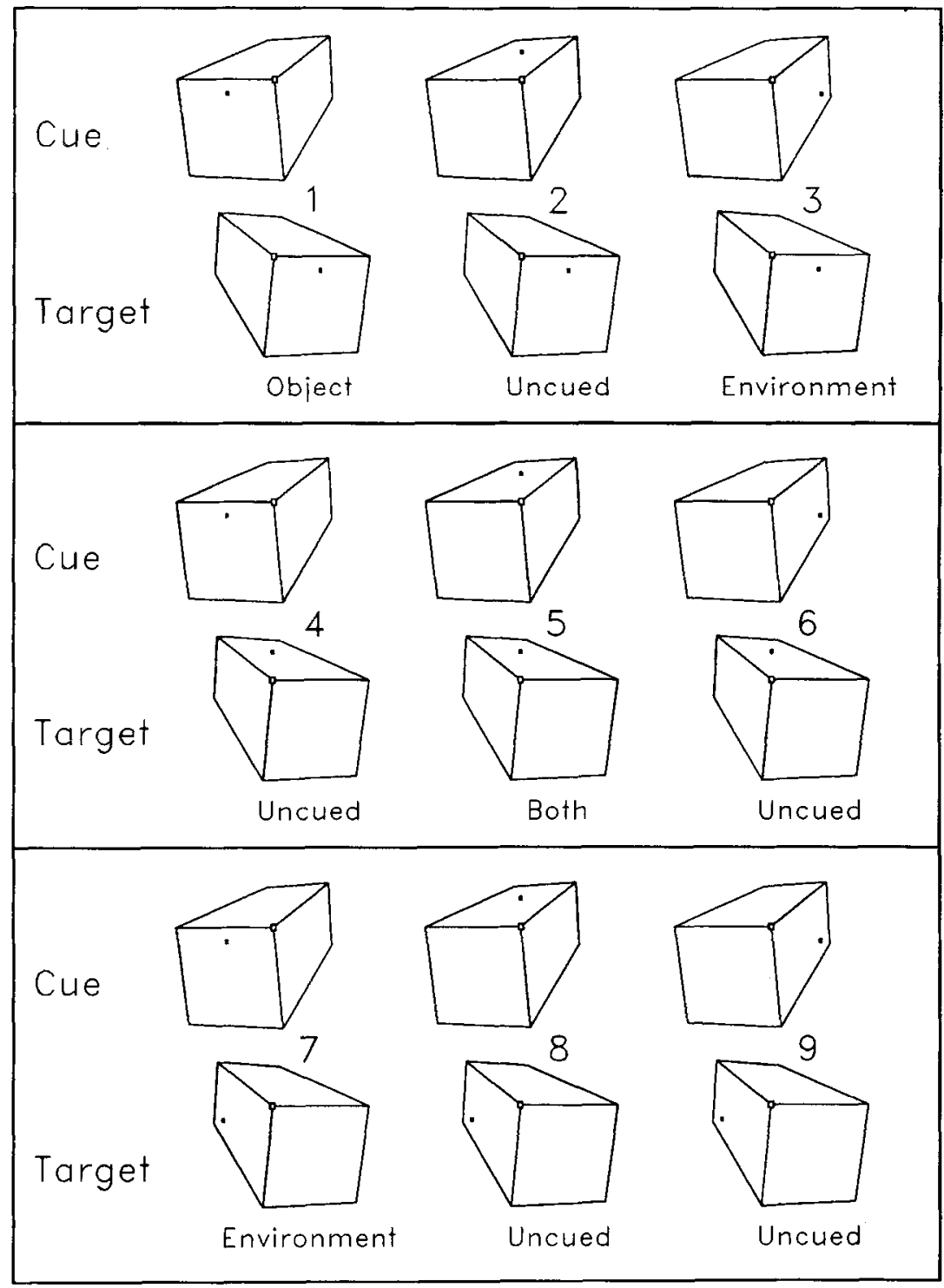

Figure 3. The nine cue-target combinations employed in Experiment 1. Each set of two rows represents a different target position group. The top row of each group shows cue location; each column shows an invariant cue location. The bottom row of each group shows target location, which remained invariant within each group. 
tion, and they were in the same location with respect to the environment in the environment condition. The one uncued condition in this group is labeled 2 in Figure 3.

When the target dot appeared on the top of the brick, there was one cued condition and there were two uncued conditions. In the both condition, the cue and target appeared in the same location with respect to both the brick and the environment (labeled 5 in Figure 3). The two uncued conditions in this group are labeled 4 and 6 in Figure 3.

Finally, when the target dot appeared on the side of the brick, there was one cued condition and there were two uncued conditions. In the cued condition (labeled 7 in Figure 3), the cue and target appeared in the same location with respect to the environment, but in a different location with respect to the brick. Accordingly, this condition was also called the environment condition. Because the two environment conditions differed with respect to the location of the target dot, as well as the relative depth relations between cue and target, we will use the terms front environment and side environment to distinguish these two conditions (i.e., Conditions 3 and 7 in Figure 3). The two uncued conditions in this group are labeled 8 and 9 in Figure 3.

The cued and uncued conditions are presented in the context of their respective target position groups because it is possible that the motion of the brick differentially affects the detection of targets appearing on different surfaces, as might occur as a result of suppressed eye movements initiated in the direction of motion. For instance, observers might suppress tracking the front of the brick as it rotates. Rafal et al. (1989) have shown that RTs are slower to targets that appear in a location to which observers have suppressed an eye movement. Thus, responses might be slower when the target appears on the front of the brick than when it appears on either the top or the side of the brick, because eye movements may have been suppressed to the front surface.

Each experimental session included 20 replications of each of the nine different conditions ( 10 for the leftward-facing brick and 10 for the rightward-facing brick) at each of the two SOAs. The first four replications were treated as practice and were not included in the results. This yielded a total of 288 experimental trials for each subject. In addition, there were 144 catch trials (not counting practice) equally distributed across the three cue locations (target location and SOA are undefined on catch trials).

\section{Results and Discussion}

The main purpose of Experiment 1 was to explore whether or not IOR could accrue to different kinds of location. In all of the experiments reported in this paper, RTs faster than 150 msec or slower than $1.5 \mathrm{sec}$ were excluded from analysis. This resulted in a $0.7 \%$ loss in the data in Experiment 1. The false alarm rate on catch trials was $2.2 \%, 1.1 \%$, and $1.5 \%$ when the cue appeared on the front, top, and side, respectively; however, the effect of cue location was not significant $[F(2,36)=2.30$, $p>.10]$.

To ensure that IOR was due to the spatial relationship between the cue and the target, it was important to control for any possible effects of motion on target detection. This control was achieved by comparing only the cued and uncued conditions that shared the same target position (i.e., the conditions that are depicted in the same target position group in Figure 3). Consequently, separate $2 \times 3$ repeated measures analyses of variance (ANOVAs) were performed on each of the three target position groups, with SOA (600 vs. $800 \mathrm{msec}$ ) and basis of cuing (e.g., Condition 1 vs. Condition 2 vs. Condi- tion 3) as the two within-subjects factors. In the front target group, there were two cued conditions and one uncued condition; in the top and side target groups, there was one cued condition and there were two uncued conditions.

Mean RTs were computed for each subject in each condition and then averaged across subjects. The resulting mean RTs for each of the cued and uncued conditions at each SOA are shown in Table 1 according to target location. Table 1 also includes a description of the relative depth (near, middle, or far) of the cue and target in each condition to facilitate discussion of this factor. Note that here, and in the following experiments, we report statistical results for SOA and the interaction of SOA with basis of cuing. However, we do this chiefly for the sake of completeness; we have no theoretical interest in these results and have nothing further to say about them.

The middle panel of Table 1 shows performance in the both condition relative to the two uncued conditions. The main effect of basis of cuing was significant $[F(2,36)=$ $6.12, p<.01]$; but there was no effect of SOA, nor was the interaction between SOA and basis of cuing significant (both $F \mathrm{~S}<1$ ). Post hoc tests involving basis of cuing showed that RTs were significantly slower in the both condition (Condition 5) than in either of the two uncued conditions (Conditions 4 and 6$)[F(1,18)=12.89, p<$ .005 , and $F(1,18)=4.08, p<.06$, respectively]. Furthermore, the two uncued conditions did not differ from one another $[F(1,18)=1.69, p>.20]$. The mean amount of IOR (cued RT - uncued RT) observed in the both condition was $18 \mathrm{msec}$. However, because the cue and target appeared in the same location with respect to both the object and the environment in this condition, the both condition does not indicate whether IOR can be obtained when location is specified independently with respect to an object or the environment. The answer to

Table 1

Mean Reaction Times at Each Level of Stimulus Onset Asynchrony (SOA) in Each of the Cued and Uncued Conditions in Experiment 1, Listed According to Target Position

\begin{tabular}{|c|c|c|c|c|c|}
\hline \multirow[b]{2}{*}{ Basis of Cuing } & \multicolumn{2}{|c|}{ Relative Depth } & \multicolumn{3}{|c|}{ SOA } \\
\hline & Cue & Target & 600 & 800 & $M$ \\
\hline \multicolumn{6}{|c|}{ Target on Front } \\
\hline 1. Object & near & near & 354 & 342 & 348 \\
\hline 2. Uncued & middle & near & 342 & 339 & 340 \\
\hline 3. Environment & & near & 370 & 356 & 363 \\
\hline$M$ & & & 355 & 346 & \\
\hline \multicolumn{6}{|c|}{ Target on Top } \\
\hline 4. Uncued & near & middle & 333 & 333 & 333 \\
\hline 5. Both & middle & middle & 350 & 357 & 354 \\
\hline 6. Uncued & & middle & 342 & 338 & 340 \\
\hline$M$ & & & 342 & 343 & \\
\hline \multicolumn{6}{|c|}{ Target on Side } \\
\hline 7. Environment & near & far & 356 & 342 & 349 \\
\hline 8. Uncued & middle & far & 342 & 334 & 338 \\
\hline 9. Uncued & far & far & 342 & 333 & 338 \\
\hline$M$ & & & 347 & 336 & \\
\hline
\end{tabular}


this question is revealed in the object and environment conditions.

The top panel of Table 1 lists performance in the object, environment, and uncued conditions when the target appeared on the front of the brick. There was a significant main effect of basis of cuing $[F(2,36)=16.98$, $p<.0001]$, a marginally significant effect of SOA $[F(1,18)=3.44, p=.08]$, and a nonsignificant interaction between basis of cuing and SOA $(F<1)$. Post hoc tests involving basis of cuing indicated that RTs were significantly slower in the object condition (Condition 1) and the environment condition (Condition 3 ) than in the uncued condition (Condition 2) $[F(1,18)=5.34, p<.05$, and $F(1,18)=27.46, p<.001$, respectively]. However, RTs in the environment condition were also significantly slower than RTs in the object condition $[F(1,18)=12.96$, $p<.005$ ]. Indeed, the mean amount of IOR in the object condition was only $8 \mathrm{msec}$, whereas the mean amount of IOR in the environment condition was $23 \mathrm{msec}$.

Thus, two noteworthy findings were obtained when the target appeared on the front of the brick. First, IOR was obtained both when location remained fixed with respect to the brick (but not the environment) and when location remained fixed with respect to the environment (but not the brick). This finding suggests that IOR can accrue to different kinds of location. However, our second finding showed that IOR was stronger when location remained fixed with respect to the environment than when it remained fixed with respect to the object, suggesting that the former type of location may have been more salient than the latter type.

Moreover, it is worth pointing out that the mean amount of IOR observed in the both condition in the top target group $(18 \mathrm{msec})$ did not reflect the sum of the two independent effects obtained in the front target group ( $23 \mathrm{msec}$ and $8 \mathrm{msec}$ ); however, the conclusion that these two types of locations are processed in a nonadditive fashion may be premature, because cue and target were less eccentric (in terms of visual angle) in the both condition than in the object and environment conditions, which may have influenced the amount of IOR obtained in any one condition. We pursued this issue further in Experiments 2 and 3.

The IOR obtained in the environment condition is also important because it diminishes the effect of depth in the interpretation of our results. According to one "depthbased" account, dots presented at different depths may appear at different locations; hence, IOR might be obtained only when the cue and target are presented in the same location with respect to the object, the environment, or both and at the same depth. Although this account is consistent with the IOR obtained in the object and both conditions (see Table 1), it cannot account for the IOR observed in the front environment condition because cue and target appeared at different depths in this conditionnamely, far and near, respectively.

Finally, performance in the side target group is listed in the bottom panel of Table 1. Unlike for the other two target location groups, there were no significant effects observed in this group: for basis of cuing, $F(2,36)=$ $1.87, p>.15$; for SOA, $F(1,18)=3.31, p>.05$; and for the interaction between basis of cuing and SOA, $F<1$. One possible explanation for the discrepancy between the front environment condition and the side environment condition concerns another depth-based account-namely, the relative depths at which the cue and target appeared in the two conditions (see, e.g., Gawryzewski, Riggio, Rizzolatti, \& Umiltà, 1987). As can be seen in Table 1, the cue appeared farther in depth than the target (on front) in the front environment condition, whereas the cue appeared nearer to the observer than the target (on side) in the side environment condition. However, an ANOVA that compared the 23-msec IOR effect in the front environment condition with the 11-msec IOR effect in the side environment condition failed to reach significance $(p>.10)$, indicating that there was no statistical basis for distinguishing the front and side environment conditions.

At this point, we do not fully understand why IOR was not observed independently in the side environment condition, though other uncontrolled stimulus differences did exist between the side environment condition and the front environment condition that may have diminished IOR. As shown in Figure 3, the target appeared on a surface (the side) that was previously occluded at the time of the cue in the side environment condition. On the other hand, the target appeared on a surface (the front) that remained in constant view throughout the trial in the front environment condition. Hence, it is possible that the attentional consequences associated with detecting a target that occurred in the same environmental location were mitigated when that environmental location was coupled with a surface that was previously out of view. Alternatively, the appearance of a previously occluded surface (or at least the oblique line defining the bottom border of that surface) may have caused a greater sensory change at that location, which in turn may have differentially affected performance in that condition. These alternatives are explored further in Experiment 2.

\section{EXPERIMENT 2}

Experiment 1 showed that IOR was obtained when location was defined with respect to an object. In Experiment 2, we tested the extent to which this effect depended on the brick per se, as opposed to more local information that was also available in the display. Consider Figure 4 . The 13 different views depicted in Figures $4 A-4 M$ correspond to the 13 views of the brick shown in Experiment 1 with the exception that all but two of the original lines were removed from the display (the dotted lines depicted in Figure 4 were not present in the actual displays). These two lines may have provided enough context in the original display to account for the results observed in $\mathrm{Ex}$ periment 1 .

For example, IOR may have been observed in the object condition of Experiment 1 because the target dot remained fixed with respect to a landmark: both the cue and 

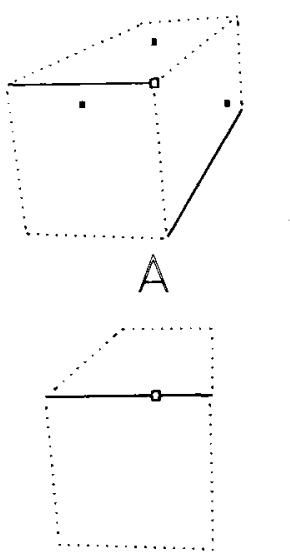

E
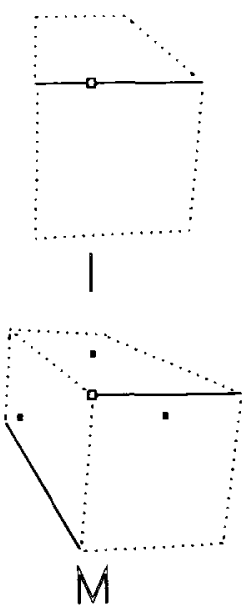
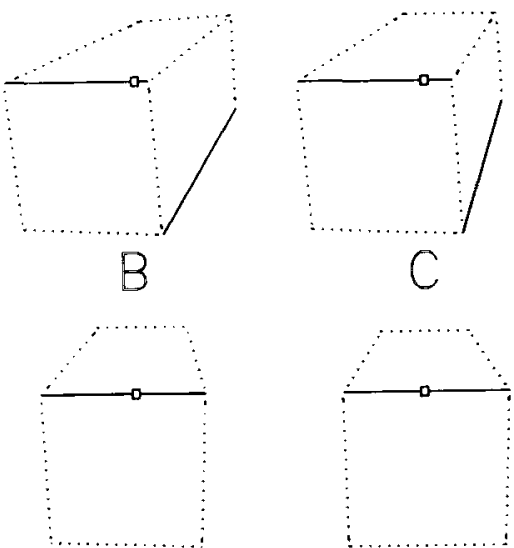

F
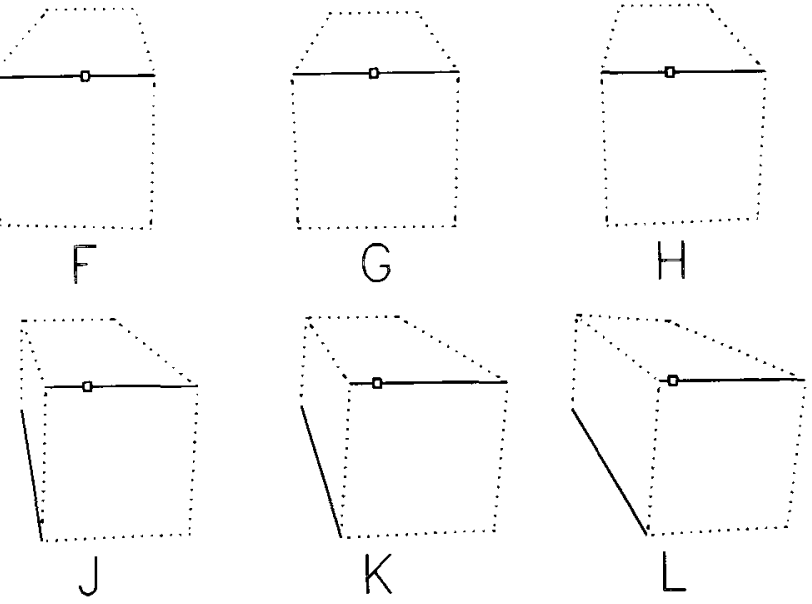

Figure 4. The 13 different views shown in Experiment 2. Note that only the long horizontal and oblique lines (and fixation square) were present in the display. The dotted lines were not present in the display shown to subjects. Figures $4 \mathrm{~A}$ and $4 \mathrm{M}$ show the three possible cue and target locations; the cues and targets were never presented simultaneously.

target appear below the horizontal line, albeit in a different environmental location. Accordingly, this "landmark" hypothesis predicts that IOR will continue to be observed in this condition even though the brick is no longer perceived. In contrast, if this feature does not provide sufficient context in which to fix a location, then IOR will no longer be observed in this condition.

On the other hand, elimination of the various line segments should have only a minimal effect on IOR when location is defined with respect to the environment, as in the both and environment conditions in Experiment 1. This experiment is also relevant to the question of whether the failure to find significant IOR in the side environment condition of Experiment 1 was due to the sudden appearance of a previously occluded surface, or to the sensory change that accompanied this sudden appearance, because there are no longer any perceived surfaces in these displays.

\section{Method}

Subjects. Twenty students from Johns Hopkins University participated in this experiment for pay. All subjects reported normal or corrected-to-normal vision.

Stimuli and Apparatus. All aspects of Experiment 2 were identical to the first experiment except that only two line segments were retained from the original display, as indicated by the solid lines in Figure 4. These line segments included the horizontal edge that separated the top surface from the front surface-called the horizontal line-and the bottom edge of the side surface-called the oblique line. These line segments were chosen because they may have provided sufficient local context in which to encode the location of the dots. For instance, the dots appeared below the horizontal line, above the horizontal line, or next to the oblique line. These locations correspond to the front, top, and side locations, respectively, used in Experiment 1. No subject reported seeing the array as anything other than two independent lines moving in opposite directions.

Procedure. Figure 5 shows the nine conditions formed from the factorial combination of the three cue locations with the three target locations. Apart from the degraded nature of the brick, the lo- 
cations of cues and targets were identical to those in Experiment 1. Accordingly, for ease of comparison, we have retained the labels for each target group and condition used in Experiment 1. However, the labels used to describe the three target position groups (front, top, and side), as well as the object and both conditions, appear in quotations to remind the reader that these terms do not apply in Experiment 2 as they did in Experiment 1.

\section{Results and Discussion}

Latencies faster than $150 \mathrm{msec}$ or slower than $1.5 \mathrm{sec}$ occurred on only $0.3 \%$ of the trials. The false alarm rate on catch trials was $0.42 \%, 0.74 \%$, and $0.42 \%$ when the cue appeared on the "front," "top," and "side," respectively; however, the effect of cue location was not significant $(F<1)$. Mean RTs were computed for each subject in each condition and then averaged across subjects. The resulting mean RTs are shown at each SOA in their respective target location groups in Table 2 .

The top panel of Table 2 shows performance in the "front" target group. There was a significant main effect of basis of cuing $[F(2,38)=9.26, p<.001]$, a significant main effect of SOA $[F(1,19)=4.31, p<.05]$, and a nonsignificant interaction between basis of cuing and SOA $(F<1)$. The main effect of SOA indicated that RTs were faster following the 600 -msec SOA than following the 800 -msec SOA. Post hoc tests involving basis of cuing indicated that RTs in the environment condition (Condition 3) were significantly slower than RTs in the uncued condition (Condition 2) $[F(1,19)=8.64, p<$ $.01]$. Hence, as expected, IOR was not affected by the elimination of the brick when location was defined with respect to the environment.

No statistical difference was found between the "object" condition (Condition 1) and the uncued condition (Condition 2) $[F(1,19)=1.0, p>.30]$. Moreover, an ANOVA designed to test the interaction between experiment (Experiment 1 vs. Experiment 2) and basis of cu-

Table 2

Mean Reaction Times at Each Level of Stimulus Onset Asynchrony (SOA) in Each of the Cued and Uncued Conditions in Experiment 2, Listed According to Target Position

\begin{tabular}{lccc}
\hline & & SOA & \\
\cline { 2 - 4 } Basis of Cuing & 600 & 800 & $M$ \\
\hline & Target on "Front" & & \\
1. "Object" & 314 & 320 & 317 \\
2. Uncued & 312 & 330 & 321 \\
3. Environment & 334 & 339 & 336 \\
$M$ & 320 & 330 & \\
& Target on "Top" & & \\
4. Uncued & 305 & 324 & 314 \\
5. "Both" & 328 & 336 & 332 \\
6. Uncued & 316 & 321 & 318 \\
$M$ & 316 & 327 & \\
& & & \\
7. Environment & Target on "Side" & 324 & 330 \\
8. Uncued & 335 & 324 & 324 \\
9. Uncued & 326 & 322 & 326 \\
$M$ & 333 & 318 & \\
\hline
\end{tabular}

ing (object/ "object"' condition vs. uncued condition) indicated that the mean amount of IOR obtained in the object condition of Experiment 1 was significantly greater than the mean amount of IOR obtained in the "object" condition in Experiment $2[F(1,37)=4.81, p<.05]$. Hence, these findings suggest that a local segment of the brick was not sufficient to fix location; apparently, location remains fixed only when it can be defined with respect to a more complete representation.

The middle panel of Table 2 shows performance in the "both" condition relative to the two uncued conditions. The main effect of SOA was significant $[F(1,19)=7.26$, $p<.02$ ], as was the main effect of basis of cuing $[F(2,36)=6.12, p<.01]$; however, the interaction between basis of cuing and SOA was not significant $[F(2,38)=2.08, p>.10]$. Like performance in the "front" target group, RTs in the "top" target group were faster following the 600-msec SOA than following the 800 -msec SOA. Post hoc tests involving basis of cuing indicated that RTs were significantly slower in the "both" condition (Condition 5) than in either of the two uncued conditions (Conditions 4 and 6) $[F(1,19)=12.67, p<$ .005 , and $F(1,19)=7.73, p<.02$, respectively]. Furthermore, the two uncued conditions did not differ from one another $[F(1,19)=2.40, p>.10]$. The mean amount of IOR observed in the "both" condition in Experiment $2(16 \mathrm{msec})$ was comparable to the mean amount of IOR observed in the both condition in Experiment 1 (18 msec), despite there being no contribution from objectbased locations in the present experiment. This confirms the observation in Experiment 1 that the two types of location have a nonadditive effect on IOR.

Performance in the "side" target group is listed in the bottom panel of Table 2. The main effect of SOA was significant $[F(1,19)=5.26, p<.05]$, indicating that $\mathrm{RTs}$ were slower following the 600 -msec SOA than following the 800-msec SOA. As in Experiment 1, the main effect of basis of cuing was nonsignificant $(F<1)$, as was the interaction between SOA and basis of cuing $(F<1)$. Hence, we failed once again to obtain IOR in the "side" environment condition. We also compared the mean amount of IOR in the "side" environment condition with the mean amount of IOR in the "front" environment condition. This ANOVA indicated a marginally significant increase in the magnitude of IOR in the "front" environment condition in comparison with the magnitude of IOR in the "side" environment condition $[F(1,19)=3.70$, $p=.07]$.

The failure to obtain significant IOR in the "side" environment condition in Experiment 2 (and in Experiment 1 ) suggests that the inhibitory mechanism was influenced by the abrupt onset of the oblique line. Inspection of Figure 4 (and Figure 2) shows that the oblique line disappeared as it moved laterally across the screen and later reappeared on the opposite side of the horizontal line. Apparently, the abrupt onset of the oblique line selectively reduced the inhibition that would have presumably accrued to that location by the prior presentation of the cue. 


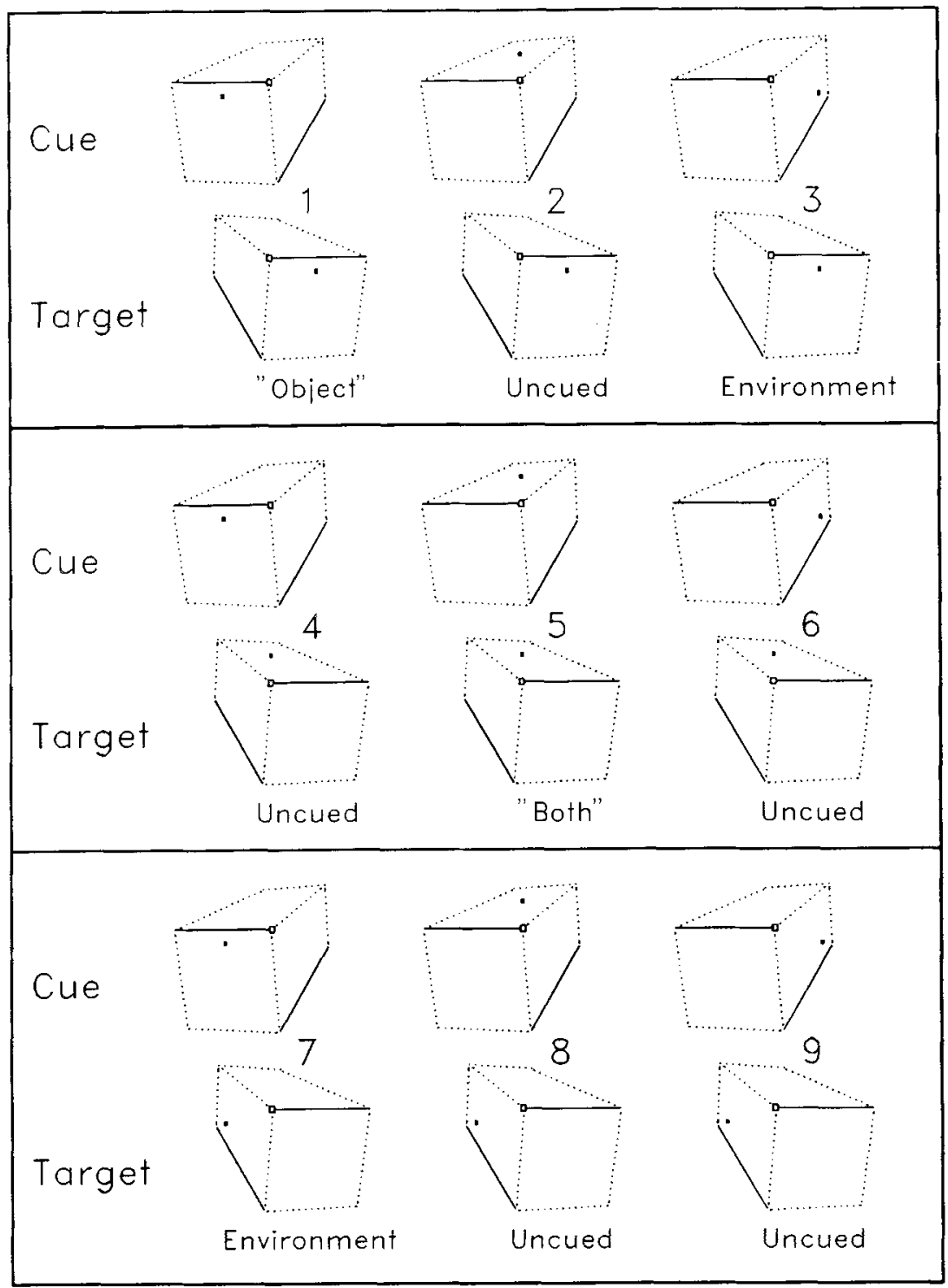

Figure 5. The nine cue-target combinations employed in Experiment 2. Each set of two rows represents a different target position group. The top row of each group shows cue location; each column shows an invariant cue location. The bottom row of each group shows target location, which remained invariant within each group. Note that the dotted lines were not actually present in the display.

\section{EXPERIMENT 3}

In the final two experiments, we focus more closely on the nature of IOR that accrues to locations specified with respect to an object. In Experiment 3, we sought to replicate the IOR obtained in the object condition in Experiment 1 by using a slightly different procedure. In addition, we also investigated further the relation between the both condition and the object condition. Accordingly, we limited the number of conditions in Experiment 3 to include only the object condition, the both condition, and their associated uncued conditions. In Experiment 4, we used this new procedure to rule out an alternative objectbased explanation of the IOR observed in the object condition in Experiment 1.

\section{Method}

Subjects. Twelve students from Johns Hopkins University participated in Experiment 3 as part of a course requirement. All subjects reported normal or corrected-to-normal vision.

Stimuli and Apparatus. The stimuli used in Experiment 3 were identical to those used in Experiment 1, with the following exceptions: First, the brick rotated only as far as the intermediate posi- 


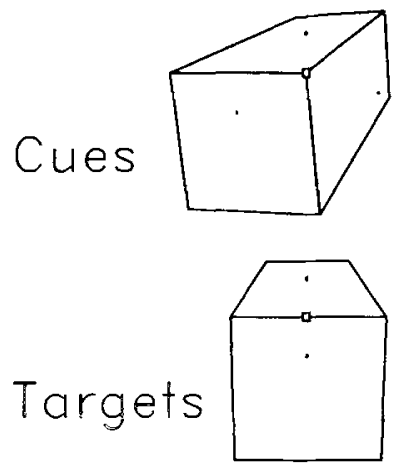

Figure 6. Cue and target locations employed in Experiment 3.

tion (see Figure 2G). Thus the total distance that the brick rotated in Experiment 3 was half the distance that the brick rotated in Experiment $1\left(18^{\circ}\right.$ vs. $\left.36^{\circ}\right)$. We introduced this change to eliminate the sudden onset of the oblique line associated with the previously occluded side. Second, there continued to be three possible cue locations as in Experiment 1, but there were now only two possible target locations at the terminal location of the brick: one located on the front surface and one located on the top surface (see Figure 6). Moreover, the location of the target dot on the front surface was lowered so that its distance from fixation (in degrees of visual angle) was the same as the target dot on the top surface $\left(2.3^{\circ}\right)$, thus allowing a more accurate comparison between the object and both conditions. The location of the front cue was altered accordingly, so that it corresponded to the same location on the front sur- face as that of the front target. When the initial and final positions of the brick were superimposed, cues appearing on the front, top, and side of the brick were all approximately $4.0^{\circ}$ from the front target dot. Cues appearing on the front and side of the brick were both approximately $5.5^{\circ}$ from the top target dot (the top cue appeared in the same location as the top target).

Procedure. The procedure was identical to that of Experiment 1, with the following exceptions: The number of different views of the brick was reduced from 13 to 7 . Each trial began with either Figure $2 \mathrm{~A}$ or $2 \mathrm{M}$ and terminated with Figure $2 \mathrm{G}$. All stimulus durations were identical to those employed in Experiment 1 until the final frame (Figure $2 \mathrm{G}$ ) was presented. Instead of being presented for either 43 or $243 \mathrm{msec}$ before the target dot was presented, as in Experiment 1, the final frame was presented for 72,272 , or $472 \mathrm{msec}$ before the target dot was presented in Experiment 3 . These durations yielded SOAs of 458,658 , and $858 \mathrm{msec}$. We included these different levels of SOA to ensure that our results were not unique to the previous levels of SOA employed in Experiments 1 and 2.

Second, there were only two target location groups in the present experiment, as is shown in Figure 7: the front target group and the top target group. In each target location group, there was one cued condition and there were two uncued conditions. The object condition (labeled $A$ in Figure 7 ) and its two associated uncued conditions (labeled $B$ and $C$ in Figure 7) occurred in the front target group. The both condition (labeled $\mathrm{E}$ in Figure 7) and its two uncued conditions (labeled D and F in Figure 7) occurred in the top target group.

Each experimental session included 20 replications of each of the six different conditions ( 10 for the leftward-facing brick and 10 for the rightward-facing brick) at each of the three SOAs. The first 4 replications were treated as practice, and were not included in the results. This yielded a total of 288 experimental trials for each subject. In addition, there were 72 catch trials (not counting prac-

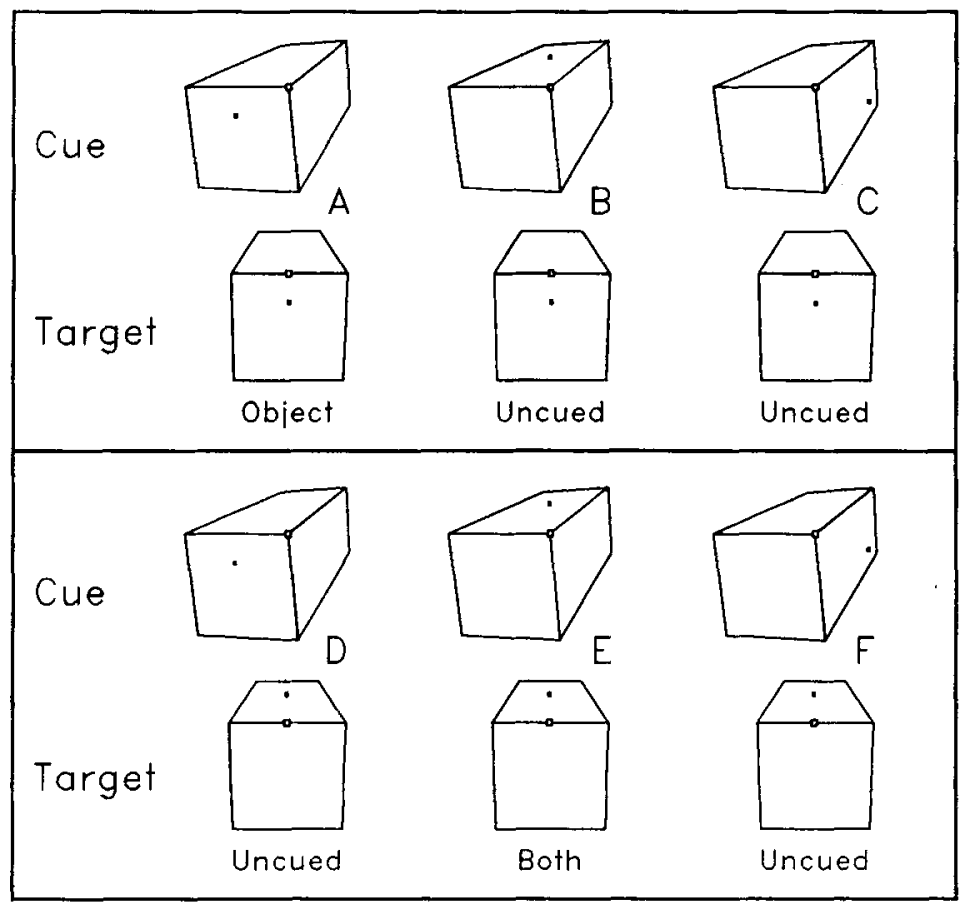

Figure 7. The six cue-target combinations employed in Experiment 3. Each set of two rows represents a different target position group. The top row of each group shows cue location; each column shows an invariant cue location. The bottom row of each group shows target location, which remained invariant within each group. 
tice trials) equally distributed across the three cue locations. Thus, catch trials occurred on one fifth of the trials in this experiment.

\section{Results and Discussion}

Latencies faster than $150 \mathrm{msec}$ or slower than $1.5 \mathrm{sec}$ occurred on $0.9 \%$ of the trials and were not analyzed. The false alarm rates on catch trials were $1.7 \%, 0.0 \%$, and $1.0 \%$ when the cue appeared on the front, top, and side, respectively; however, the effect of cue location was not significant $[F(2,22)=2.37, p>.10]$. Mean RTs for each condition at each SOA are shown in Table 3 in their respective target location groups.

The top panel of Table 3 shows performance in the front target group. There was a significant main effect of SOA $[F(2,22)=8.03, p<.005]$. Post hoc tests indicated that RTs were faster in the 658-msec SOA condition than in either the 458-msec SOA condition $[F(1,11)=8.35, p<$ $.02]$ or the $858-\mathrm{msec}$ SOA condition $[F(1,11)=19.89$, $p<.001]$. The interaction between SOA and basis of cuing was not significant $(F<1)$. There was also a significant main effect of basis of cuing $[F(2,22)=7.83, p<$ $.005]$. Post hoc tests involving basis of cuing indicated that RTs in the object condition (Condition A) were significantly slower than RTs in either of the uncued conditions (Conditions $\mathrm{C}$ and $\mathrm{B})[F(1,11)=10.18, p<.01$, and $F(1,11)=9.00, p<.02$, respectively]. However, the two uncued conditions did not differ from one another $[F(1,11)=1.21, p>.25]$.

The bottom panel of Table 3 shows performance in the top target group. There was a significant main effect of SOA $[F(2,22)=10.80, p<.001]$. Like performance in the front target group, post hoc tests indicated that RTs were faster in the 658-msec SOA condition than either the 458-msec SOA condition $[F(1,11)=15.92, p<.01]$ or the 858-msec SOA condition $[F(1,11)=21.34, p<$ $.001]$. The interaction between SOA and basis of cuing was not significant $[F(2,22)=1.06, p>.35]$. There was also a significant main effect of basis of cuing $[F(2,22)=$

Table 3

Mean Reaction Times at Each Level of Stimulus Onset Asynchrony (SOA) in Each of the Cued and Uncued Conditions in Experiment 3 Listed According to Target Position

\begin{tabular}{|c|c|c|c|c|}
\hline \multirow[b]{2}{*}{ Basis of Cuing } & \multicolumn{4}{|c|}{ SOA } \\
\hline & 458 & 658 & 858 & $M$ \\
\hline \multicolumn{5}{|c|}{ Target on Front } \\
\hline $\begin{array}{l}\text { A. Object } \\
\text { B. Uncued } \\
\text { C. Uncued }\end{array}$ & $\begin{array}{l}327 \\
310 \\
312\end{array}$ & $\begin{array}{l}306 \\
293 \\
303\end{array}$ & $\begin{array}{l}343 \\
318 \\
318\end{array}$ & $\begin{array}{l}325 \\
307 \\
311\end{array}$ \\
\hline$M$ & 316 & 301 & 326 & \\
\hline \multicolumn{5}{|c|}{ Target on Top } \\
\hline $\begin{array}{l}\text { D. Uncued } \\
\text { E. Both } \\
\text { F. Uncued }\end{array}$ & $\begin{array}{l}312 \\
338 \\
326\end{array}$ & $\begin{array}{l}294 \\
320 \\
300\end{array}$ & $\begin{array}{l}328 \\
351 \\
317\end{array}$ & $\begin{array}{l}311 \\
336 \\
314\end{array}$ \\
\hline$M$ & 325 & 305 & 332 & \\
\hline
\end{tabular}

12.35, $p<.001$ ]: RTs were slower in the both condition (Condition $\mathrm{E}$ ) than in either of the uncued conditions (Conditions D and F) $[F(1,11)=18.49, p<.002$, and $F(1,11)=14.82, p<.005$, respectively]. Moreover, the two uncued conditions did not differ from one another $(F<1)$.

We next compared the 16-msec effect of IOR in the object condition with the 24-msec effect of IOR in the both condition in a separate ANOVA that included target position (front vs. top), basis of cuing (object/both condition vs. uncued condition), and SOA as the three withinsubjects factors. Although IOR was slightly greater in the both condition than in the object condition, the critical interaction between target position and basis of cuing was not significant $(F<1)$, indicating that fixing location with respect to both the object and the environment does not increase the amount of IOR above that obtained when location is fixed solely with respect to the object. Thus, the results of Experiment 1 were successfully replicated in Experiment 3 through the use of a slightly different procedure, in which the abrupt onset of the previously occluded side was eliminated.

\section{EXPERIMENT 4}

In this experiment, we investigated whether the location of the cue and target in the object condition in Experiments 1 and 3 was possibly confounded with a more basic object, the front surface. Figure 8 shows the location of the cues, targets, and fixation square used in Experiment 4 . Note that the fixation square was moved to the front surface. Again, there were three possible cue locations in this experiment; one cue appeared above and to the left or right of fixation on the front surface, one cue appeared below and to the left or right of fixation on the front surface, and one cue appeared to the right or left of fixation on the side surface (depending on the orientation of the brick). The three possible target locations for the leftward-facing brick all appeared within the front surface, as shown in Figure 8A. The three target locations for the rightward-facing brick were the same as for the leftward-facing brick, except that a target was located to the right of fixation instead of to the left of fixation, as shown in Figure 8B. Three target locations were required for each brick in order to equate the physical distance between cued locations and uncued locations (see below). Inhibition of return to locations specified with respect to the brick can be determined by observing whether RTs are slower when the cue and target appear in the identical location on the front surface (e.g., above fixation) relative to when the cue and target appear in different locations on the front surface. In contrast, if IOR is objectbased, RTs in these two conditions should not differ from one another. However, if IOR is object-based, both of these conditions should differ from a condition in which the cue appears on a different (side) surface from the target. 


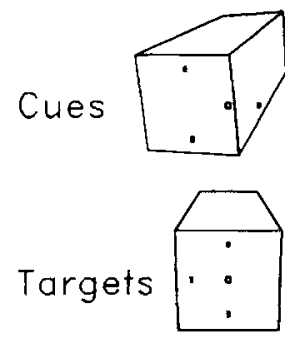

A
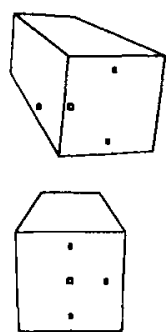

B
Figure 8. Location of the cues, targets, and fixation square in Experiment 4. (A) The three cue locations (top) and the three target locations (bottom) in the leftward-facing brick; (B) the three cue locations (top) and the three target locations (bottom) in the rightwardfacing brick.

\section{Method}

Subjects. Twelve students from Johns Hopkins University participated in Experiment 3 as part of a course requirement. All subjects reported normal or corrected-to-normal vision.

Stimuli and Apparatus. The stimuli used in Experiment 4 were identical to those used in Experiment 3, with the following exceptions. First, as is shown in Figure 8, the location of the fixation square, as well as the target stimuli, were confined to the front surface. Cues could appear either above or below the centrally located fixation square, or on the side. Cues appearing above and below fixation on the front surface were $5.1^{\circ}$ and $4.6^{\circ}$ from the fixation square, respectively. Cues on the side appeared at the same height as the fixation square and were $3.0^{\circ}$ away. The three targets were each located $3.0^{\circ}$ from fixation. Although there were three possible target locations, only two target locations were associated with each cue (see Figure 9). When the cue appeared on the front surface of the leftward-facing brick (either above or below fixation), the target could appear either in the same location on that surface or to the left of fixation (see Figure 8A). In contrast, when the cue appeared on the front surface of a rightward-facing brick, the target could appear either in the same location on that surface, or to the right of fixation (see Figure $8 \mathrm{~B}$ ). When the cue appeared on the side surface, the target could appear either above or below fixation. Thus, targets that appeared either above or below fixation appeared twice as often as targets that appeared to the left or right of fixation. Consequently, latencies to targets appearing above or below fixation might be speeded given their greater likelihood. This should operate against location-based IOR because a target shown in the identical location as a cue appeared only above or below fixation (see Figure 9).

The mapping between cue and target was constrained in this manner so that targets that appeared in the identical location as the cue (i.e., either above or below fixation) were approximately the same physical distance away from the initial location of each cue as targets that appeared in a different location than the cue. Specifically, when the initial and final positions of the brick were superimposed, the cues that appeared above fixation on the front surface were $4.2^{\circ}$ away from targets that appeared above fixation. The cues that appeared below fixation on the front surface were $3.4^{\circ}$ away from targets that appeared below fixation. The same cues were both approximately $3.2^{\circ}$ away from targets that appeared to the left or right of fixation. The cues that appeared on the side were approximately $4.0^{\circ}$ away from both possible target locations (either above or below fixation). Hence, slower RTs when the cue and target appear in the identical location cannot be attributed to any residual IOR associated with the environmental location of the cue on the screen (see, e.g., Maylor \& Hockey, 1985).

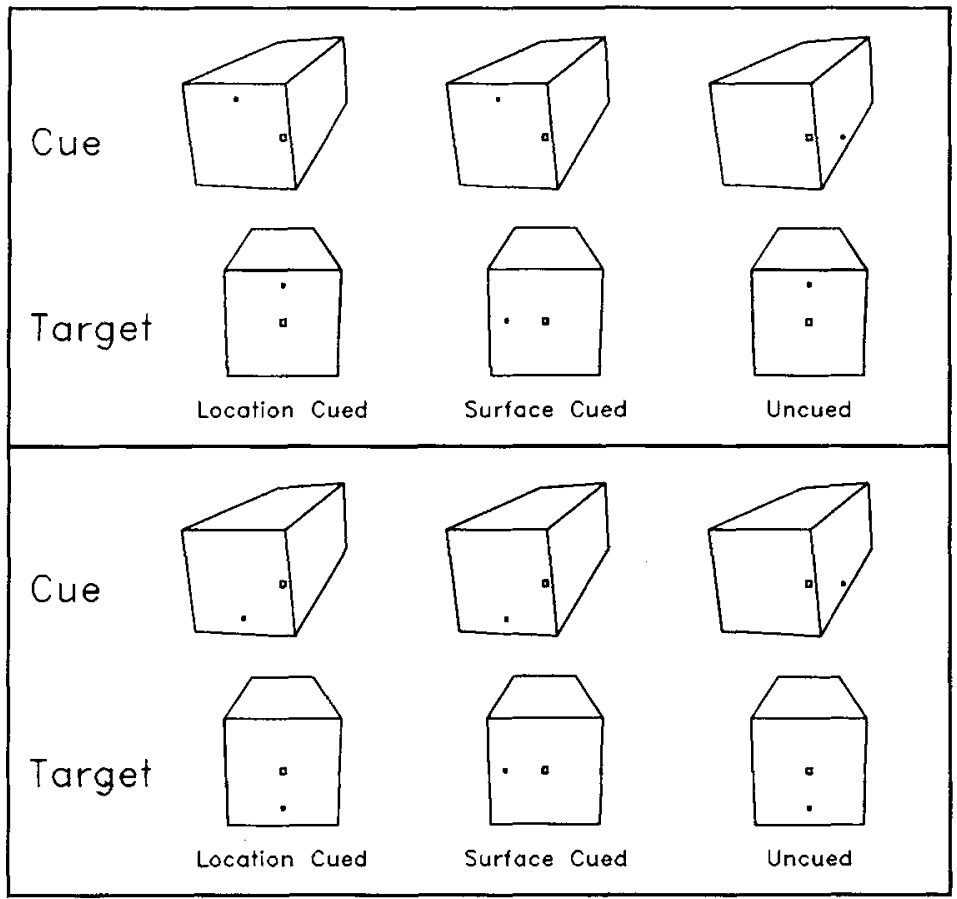

Figure 9. The six cue-target combinations employed in Experiment 4. The leftmost column shows the two trial types in the location cued condition; the middle column shows the two trial types in the surface cued condition; and the rightmost column shows the two trial types in the uncued condition. 
Table 4

Mean Reaction Times at Each Level of Stimulus Onset Asynchrony (SOA) in Each of the Cued and Uncued Conditions in Experiment 4

\begin{tabular}{cccc}
\hline & \multicolumn{3}{c}{ SOA } \\
\cline { 2 - 4 } Basis of Cuing & 458 & 658 & $M$ \\
\hline Location cued & 324 & 335 & 330 \\
Surface cued & 313 & 320 & 316 \\
Uncued & 317 & 316 & 317 \\
$M$ & 318 & 324 & \\
\hline
\end{tabular}

Procedure. The procedure was similar to that in Experiment 3 , except that only two levels of SOA, 458 and $658 \mathrm{msec}$, were used. The two instances of each of the three conditions employed in Experiment 3 are depicted in Figure 9. In the location cued condition (the leftmost column in Figure 9), the target appeared in exactly the same location on the front surface as the cue, but in different environmental locations. The location cued condition corresponds to the object condition in Experiments 1 and 3. In the surface cued condition (the middle column in Figure 9), the cue and target appeared in different locations on the front surface and in different environmental locations. Finally, in the uncued condition (the rightmost column in Figure 9), the cue and target appeared on different surfaces and in different environmental locations.

Each experimental session included 28 replications of each of the six different conditions ( 14 for the leftward-facing brick and 14 for the rightward-facing brick) at each of the two SOAs. The first four replications were treated as practice, and were not included in the results. This yielded a total of 288 experimental trials for each subject. In addition, there were 72 catch trials (not counting practice trials) equally distributed across the three cue locations. Thus, catch trials occurred on one fifth of the trials in this experiment.

\section{Results and Discussion}

Latencies less than $150 \mathrm{msec}$ or greater than $1.5 \mathrm{sec}$ were discarded. As a result, $0.6 \%$ of the trials were not analyzed. The false alarm rates on catch trials were $3.1 \%$, $1.7 \%$, and $0.7 \%$ when the cue appeared above fixation, below fixation, or on the side, respectively; however, the effect of cue location was not significant $[F(2,22)=1.22$, $p>$.30]. Mean RTs for each of the three conditions at each SOA are depicted in Table 4.

The main purpose of Experiment 4 was to determine whether IOR could be specific to a particular location within a surface. The main effect of basis of cuing was significant $[F(2,22)=15.62, p<.0001]$. Neither the main effect of SOA nor the interaction between SOA and basis of cuing was significant $[F(1,11)=1.54, p>.20$, and $F(2,22)=1.80, p>.10$, respectively]. Post hoc tests indicated that RTs were significantly slower in the location cued condition than in either the surface cued condition (14-msec difference) or the uncued condition (13msec difference) $[F(1,11)=28.09, p<.001$, and $F(1,11)=15.13, p<.01$, respectively]. There was no difference between the surface cued condition and the uncued condition $(F<1)$. Hence, the conclusion that IOR can accrue to locations fixed within an object can be stated with more confidence in light of these findings.

\section{GENERAL DISCUSSION}

We began this study with the purpose of investigating the spatial domain of IOR and in particular the question of whether or not IOR could accrue to locations defined with respect to an object. Previous investigations have shown that inhibition can accrue to spatially invariant objects as well as to fixed, environmental locations (Tipper et al., 1991; Tipper et al., in press). However, such a dichotomy overlooks the spatial structure inherent in the structural descriptions of objects. In contrast, our study emphasized the spatial similarity between objects and the environment and showed clearly that the locations defined with respect to an object are among the locations "tagged" by IOR, as are the locations defined with respect to the environment. However, though we focused primarily on location-based IOR in the present study, we do not wish to deny the significance of object-based IOR (Tipper et al., 1991; Tipper et al., in press). Rather, the present results complement object-based IOR and suggest that the mechanisms underlying IOR are even more flexible than previously considered, perhaps further underlining the functional significance of this process.

In particular, our results are compatible with the notion that IOR has two components that correspond to functionally different processing states of the organism. The object-based component is associated with global processing of object-based descriptions. In these circumstances, the description of the object as a whole is tagged by the inhibitory mechanism regardless of the object's environmental location (Tipper et al., 1991; Tipper et al., in press). In contrast, the location-based component is associated with local processing and thus is tied to locations defined with respect to a particular spatial medium. However, as the present results show, this spatial medium need not be confined to the environment. Rather, an object may function as a "microenvironment" and the inhibitory mechanism may tag distinct locations that remain fixed with respect to an object. Thus, this mechanism combines the relative processing advantages previously ascribed to tagging spatially fixed, environmental locations and spatially invariant objects (Maylor \& Hockey, 1985; Posner \& Cohen, 1984; Tipper et al., 1991; Tipper et al., in press).

We should point out, however, that while our results suggest that location remained fixed with respect to the brick (or a face of the brick) following depth rotation, these results need not imply that location is defined with respect to a three-dimensional object-based coordinate frame of reference (Marr, 1982; Marr \& Nishihara, 1978). Consequently, our results do not entail that inhibition will accrue to locations specified by an object across all possible transformations. Other accounts of structural descriptions have recently been proposed to account for certain observed invariances in human object recognition that nevertheless do not entail complete viewpoint invariance 
(Biederman \& Cooper, 1992; Biederman \& Gerhardstein, 1993; Hummel \& Biederman, 1992). Indeed, many studies in human object recognition suggest that the specification of location within the structural description of an object is altered when the object is transformed around the line of sight (Gibson \& Peterson, in press; Jolicoeur, 1985; Tart \& Pinker, 1989). For instance, the location top might be relabeled bottom in the structural description of an object following a $180^{\circ}$ rotation in the picture plane, presumably because the specification of location within a structural description is at least partially dependent on viewpoint. In such cases, IOR to locations specified with respect to an object may fail because the specification of location has changed across the two views, thereby causing the cued location to become functionally uncued.

Of course, the processes underlying IOR need not be constrained to operate on the same object descriptions as those used in object recognition. Kahneman and Treisman (1984; Kahneman, Treisman, \& Gibbs, 1992) have argued that the object descriptions (or "object files" in their terminology) underlying various object-based effects in visual attention may be "updated" with information obtained following recognition. One result of such updating may be a specification of location that is functionally equivalent to an object-based coordinate frame of reference. Hence, IOR to locations specified by an object may be possible even following picture plane rotations (see also Driver \& Halligan, 1991). We hope to address this issue in a subsequent report.

Although our results are compatible with the notion that object-based IOR is functionally distinct from locationbased IOR, our finding that inhibition can accrue to locations specified by an object does raise questions about this distinction. For instance, what controls whether the object description as a whole is tagged or whether a location within the object description is tagged? More specifically, does the distinction between object-based IOR and location-based IOR to locations defined with respect to an object depend solely on the spatial extent of the cue? Answers to this question may be provided by experimental conditions that simultaneously manipulate which object, as well as which location defined with respect to an object, is cued.

The present findings may provide some preliminary evidence concerning this question, but only if each face of the brick can be considered as a more basic object than the brick as a whole. For instance, the results of Experiment 4 indicated that IOR was obtained only when the cue and target shared the identical location within the front face of the brick; the mean amount of IOR obtained when the cue and target appeared within the same surface (or object) was no different than the mean amount of IOR obtained when they appeared on different surfaces (or objects). This finding suggests that IOR may be associated with the global object description only when the entire object is cued. Hence, for the purposes of IOR, cuing a local region of an object may not entail tagging the global object description (Peterson \& Gibson, 1991; cf. Humphreys \& Riddoch, 1992). This issue is important because it blurs the functional distinction between object-based and location-based IOR; for the purposes of IOR, an object may just be a location, albeit a larger location than the intraobject locations employed in this study. However, this issue awaits more definitive experiments in which more distinct objects are employed.

Another issue raised by the present findings concerns how inhibition to a location is combined when location can be defined with respect to both an object and the environment. In general, our results suggest that inhibition accrues to these two types of location in a nonadditive fashion: The average amount of IOR observed in the both condition in Experiment 1 and 2 was essentially the same (18 vs. $16 \mathrm{msec}$, respectively), despite there being no contribution from objects in Experiment 2. This nonadditivity of inhibition was also noted in Experiment 1, where the mean amount of IOR in the both condition did not reflect the sum of the IOR obtained in the environment and object conditions when the target appeared on the front of the brick, and again in Experiment 3 where the mean amount of IOR in the both condition did not differ significantly from the mean amount of IOR in the object condition. Hence, inhibition to only one type of location may dominate performance in cases in which both are specified. Indeed, the results of Experiment 1 indicated that IOR was larger when locations remained fixed with respect to the environment than when they remained fixed with respect to the brick, suggesting a possible basis for this domination. In this view, IOR obtained in the both condition may reflect to a greater extent inhibition that accrues to environment-based locations than inhibition that accrues to object-based locations, because IOR is stronger in the former instance.

Of course, the difference in IOR observed when location was specified with respect to the environment in comparison with when it was specified with respect to an object in Experiment 1 represents an important issue in its own right. No doubt, this difference in IOR reflects, in part, differences in the computational requirements underlying the invariant specification of location in environment-based and object-based descriptions. Thus, in addition to knowing the kinds of transformations that can produce IOR to locations specified with respect to an object, further research must also focus on the question of whether or not the magnitude of IOR changes as a function of these various transformations. In fact, the mean amount of IOR in the object condition did increase from $8 \mathrm{msec}$ in Experiment 1, in which the brick rotated $36^{\circ}$, to 16 and 14 msec in Experiments 3 and 4, respectively, in which the brick rotated only $18^{\circ}$, though degree of rotation was not the only difference between the various experiments.

Nevertheless, whatever the reason for the difference in IOR observed when location was specified with respect to the environment as opposed to when it was specified with respect to an object in Experiment 1, the present find- 
ings clearly show that the spatial domain of IOR must be expanded to include both environment-based and objectbased locations. In turn, by showing that object-based descriptions can influence spatial processes (in the form of location-based IOR), the present results also expand the range of potential interactions between spatial and object components in the visual system.

\section{REFERENCES}

Abrams, R. A., \& Dobkins, R. S. (in press). Inhibition of return: Effects of attentional cueing on eye movement latencies. Journal of Experimental Psychology: Human Perception \& Performance.

Baylis, G., \& DrIVER, J. (1993). Visual attention and objects: Evidence for the hierarchical coding of location hypothesis. Journal of Experimental Psychology: Human Perception \& Performance, 19, $451-470$.

Biederman, I. (1987). Recognition-by-components: A theory of human image understanding. Psychological Review, 94, 115-147.

Biederman, I., \& CoOper, E. E. (1992). Size invariance in visual object priming. Journal of Experimental Psychology: Human Perception \& Performance, 18, 121-133.

Biederman, I., \& Gerhardstein, P. C. (1993). Recognizing depthrotated objects: Evidence and conditions for 3D viewpoint invariance. Journal of Experimental Psychology: Human Perception \& Performance, 19, 1162-1182.

Driver, J., \& Halligan, P. W. (1991). Can visual neglect operate in object-centred co-ordinates? An affirmative single-case study. Cognitive Neuropsychology, 8, 475-496.

Egly, R., Rafal, R. D., \& HeNIK, A. (1992, November). Reflexive and voluntary orienting in detection and discrimination. Poster presented at the meeting of the Psychonomic Society, St. Louis.

ERIKSEN, C. W., \& YEH, Y. (1985). Allocation of attention in the visual field. Joumal of Experimental Psychology: Human Perception \& Performance, 11, 583-597.

Farah, M. J., BrunN, J. L., Wong, A. B., Wallace, M. A., \& CarPENTER, P. A. (1990). Frames of reference for allocating attention to space: Evidence from the neglect syndrome. Neuropsychologia, 28, 335-347.

GaWryszewski, L. G., Riggio, L., Rizzolatti, G., \& Umilta, C. (1987). Movements of attention in the three spatial dimensions and the meaning of the "neutral" cues. Neuropsychologia, 25, 19-29.

Gibson, B. S., \& Peterson, M. A. (in press). Does orientationindependent object recognition precede orientation-dependent recognition? Evidence from a cuing paradigm. Joumal of Experimental Psychology: Human Perception \& Performance.

Hummel, J. E., \& Biederman, I. (1992). Dynamic binding in a neural network for shape recognition. Psychological Review, 99, 480-517.

HUMPHREYS, G. W., \& RIDDOCH, M. J. (1992). Interactions between object and space systems revealed through neuropsychology. In D. E. Meyers \& S. Kornblum (Eds.), Attention and performance XIV (pp. 143-162). Cambridge, MA: MIT Press.

JOLICOEUR, P. (1985). The time to name disoriented natural objects. Memory \& Cognition, 13, 289-303.

KahNeman, D., \& Treisman, A. (1984). Changing views of attention and automaticity. In R. Parasuraman \& D. R. Davies (Eds.), Varieties of attention (pp. 29-61). New York: Academic Press.

Kahneman, D., Treisman, A., \& GibBs, B. J. (1992). The reviewing of object files: Object-specific integration of information. Cognitive Psychology, 24, 175-219.

KLEIN, R. (1988). Inhibitory tagging system facilitates visual search. Nature, 334, 430-431.

KWAK, H.-W., \& EGETH, H. (1992a). Consequences of allocating attention to locations and to other attributes. Perception \& Psychophysics, 51, 455-464.

KWAK, H.-W., EGETH, H. (1992b, November). Testing attentional and motor explanations of inhibition of return. Paper presented at the meeting of the Psychonomic Society, St. Louis.

MARR, D. (1982). Vision. San Francisco: W. H. Freeman.

MARR, D., NishihaRA, H. K. (1978). Representation and recognition of three-dimensional shapes. Proceedings of the Royal Society of London: Series B, 200, 269-294.

MAYLOR, E. (1985). Facilitory and inhibitory components of orienting in visual space. In M. I. Posner \& O. S. M. Marin (Eds.), Attention and performance $X I$ (pp. 189-204). Hillsdale, NJ: Erlbaum

MAYLOR, E., \& HoCKey, R. (1985). Inhibitory components of externally controlled covert orienting in visual space. Joumal of Experimental Psychology: Human Perception \& Performance, 11, 777-787.

Peterson, M. A., \& GiBson, B. S. (1991). Directing spatial attention within an object: Altering the functional equivalence of shape descriptions. Journal of Experimental Psychology: Human Perception \& Performance, 17, 170-182.

Pinker, S. (1984). Visual cognition: An introduction. Cognition, 18, 1-63.

Posner, M. I., \& Cohen, Y. (1984). Components of visual orienting. In H. Bouma \& D. G. Bouwhuis (Eds.), Attention and performance $X$ (pp. 531-556). Hillsdale, NJ: Erlbaum.

Posner, M. I., Cohen, Y., Choate, L., Maylor, E., \& Hockey, R. (1984). Sustained concentration: Passive filtering or active orienting? In S. Kornblum \& J. Requin (Eds.), Preparatory states and processes (pp. 49-65). Hillsdale, NJ: Erlbaum.

Posner, M. I., Rafal, R. D., Choate, L., \& Vaughan, J. (1985). Inhibition of return: Neural basis and function. Cognitive Neuropsychology, 2, 211-228.

Rafal, R. D., Calabresi, P. A., Brennan, C. W., \& Sciolto, T. K. (1989). Saccade preparation inhibits reorienting to recently attended locations. Journal of Experimental Psychology: Human Perception \& Performance, 15, 673-685.

Rock, I. (1973). Orientation and form. New York: Academic Press. Rock, I., DiVIta, J., \& Barbeito, R. (1981). The effect on form perception of change of orientation in the third dimension. Journal of Experimental Psychology: Human Perception \& Performance, 7, 719-732.

TARR, M. J., \& PINKER, S. (1989). Mental rotation and orientationdependence in shape recognition. Cognitive Psychology, 21, 233-282.

TARR, M. J., \& Pinker, S. (1990). When does human object recognition use a viewer-centered reference frame? Psychological Science, 1, 253-256.

Terry, K. M., Valdes, L. A., \& Neill, T. (1992). Does “inhibition of retum" occur in discrimination tasks? Paper presented at the meeting of the Eastern Psychological Association.

TiPPER, S. P., Brehaut, J. C., \& DrIver, J. (1990). Selection of moving and static objects for the control of spatially directed action. Joumal of Experimental Psychology: Human Perception \& Performance, 16, 492-504.

TIPPER, S. P., DrIVER, J., \& WEAVER, B. (1991). Short report: Objectcentered inhibition of return of visual attention. Quarterly Journal of Experimental Psychology, 43A, 289-298.

Tipper, S. P., Weaver, B., Jerreat, L. M., Burak, A. L. (in press). Object- and environment-based inhibition of return of visual attention. Journal of Experimental Psychology: Human Perception \& Performance.

Wolfe, J. M., \& Pokorny, C. W. (1990). Inhibitory tagging in visual search: A failure to replicate. Perception \& Psychophysics, 48, 357-362.

\section{NOTES}

1. The precise mechanism by which intraobject locations remain fixed across different views of an object, as well as the conditions under which they do so, is currently a matter of some debate in the literature (Biederman \& Gerhardstein, 1993; Gibson \& Peterson, in press; Hummel \& Biederman, 1992; Jolicoeur, 1985; Marr, 1982; Tarr \& Pinker, 1990). Nevertheless, while resolution of this debate is critical to the precise 
form that object representations may take (and consequently, to the stimulus conditions under which location-based processing might or might not be observed within an object), it need not retard pursuit of the more general question of whether or not IOR can accrue to locations specified with respect to an object, at least in some situations.

2. We assume that location $\mathrm{Obj} 4$ is distinct from location $\mathrm{Obj} 3$ because observers were allowed to see the brick undergoing a continuous transformation in depth. Hence, it is readily apparent that one side has become occluded while the other side has become exposed. Of course, the two sides might be given functionally equivalent descriptions under more constrained viewing conditions (see, e.g., Rock, DiVita, \& Barbeito, 1981).

3. The specification of the apparent depths of the cue and target is not crucial to the design of the experiment. They are included here to facilitate discussion of some alternative explanations of our results (described later) that focus on the relative depths of the dots.

(Manuscript received April 9, 1993;

revision accepted for publication August 2, 1993.) 